Preference is given to letters commenting on contributions published recently in the JRSM. They should not exceed 300 words and should be typed double spaced

\section{Home or hospital: choices at the end of life}

I wonder whether Barbara Gomes and Irene Higginson, who wrote the excellent editorial on place of death (September $2004 J R S M^{1}$ ), would consider that a poll of RSM Fellows might provide useful data? I have seen only two formal papers, both from the USA, regarding the medical technology health workers would want for themselves at the end of life. One disclosed that the great majority of doctors in North Carolina would refuse cardiopulmonary resuscitation and tube feeding if terminally ill. ${ }^{2}$ The other concluded that physicians and nurses who have extensive exposure to hospitals and sick patients are unlikely to wish aggressive treatment if they become terminally ill, demented, or in a persistent vegetative state. ${ }^{3}$

I suspect that most British health professionals would be similarly reluctant to have much medical technology applied to them at the end of life, and, by what seems an obvious extension, would rather die at home than in hospital.

Personally, if I do not die suddenly, I want to die at home, in very familiar surroundings, with my beloved cat and partner next to me, and with the music of Shirley Bassey as loud as possible.

\section{Michael Irwin}

15 Hovedene, Cromwell Road, Hove BN3 3EH, UK

E-mail: michael-hk.irwin@virgin.net

\section{REFERENCES}

1 Gomes B, Higginson I. Home or hospital? Choices at the end of life. J R Soc Med 2004;97:413-14

2 Brunetti L, Carperos S, Westlund R. Physicians' attitudes towards living wills and cardiopulmonary resuscitation. J Gen Intern Med 1991;6:323-9

3 Gillick M, Hesse K, Mazzapica N. Medical technology at the end of life - what would physicians and nurses want for themselves? Arch Intern Med 1993; 153:2542-7

\section{Medical abbreviations}

Das-Purkayastha and colleagues (September $2004 J_{R S M}^{1}$ ) found that half of commonly used abbreviations in ear, nose and throat surgery were unclear to more than $90 \%$ of junior doctors from other specialties. Though I applaud their study, I disagree with one of their proposed solutions: to ban abbreviations altogether (the other was to distribute a list of those acceptable, with explanations).

Physicians, especially cardiologists of which I am one, like to use or invent abbreviations and acronyms. ${ }^{2}$ The use of abbreviations or acronyms is sometimes necessary to technical world, especially to avoid repetition of long, tongue-twisting and space-occupying terminologies. The problem with the abbreviations and acronyms is not the endless number of new ones but the fact that many of them are not defined when first used. Medical journals are not exempt from this criticism, ${ }^{3}$ and my proposed remedy goes under the acronym PLEASE- - Plea to Let Each Acronym (or Abbreviation) be Spelled out Every time. ${ }^{4}$

\section{Tsung O Cheng}

George Washington University Medical Center, Washington DC 20037, USA E-mail: tcheng@mfa.gwu.edu

\section{REFERENCES}

1 Das-Purkayastha P, McLeod K, Canter R. Specialist medical abbreviations as a foreign language. $J$ R Soc Med 2004;97:456

2 Cheng TO. Acronyms of cardiologic trials-2002. Int $J$ Cardiol 2003;91:261-351

3 Cheng TO. Acronym aggravation. Br Heart J 1994;71:107-9

4 Cheng TO. Plea to Let Each Acronym be Spelled out Every time (PLEASE). Eür Heart $\bar{J} 199 \overline{5} ; \mathbf{1 6}: \overline{29} 2$

\section{Helmets for cyclists and the ethics of legislation}

With regard to the paper by Professor Sheikh and his colleagues (June $2004 J R S M^{1}$ ) and the subsequent critical correspondence, no argument on effectiveness can be valid unless related to a particular helmet. Helmets have a centuries-old history and have been designed to protect against specific sources and sites of injury. In 1952, during the Korean War, the Admiralty raised a requirement for a protective helmet for Naval aircrew. It stemmed from reports of ditchings in which pilot or observer failed to abandon the sinking aircraft as a result of concussion following an apparently minor head injury. It was triggered by an accident in which a pilot was scalped when his aircraft went into a deck-landing barrier. I was serving at the RAF Institute of Aviation Medicine at the time and was tasked with developing the helmet. The RAF were not interested. Cade, ${ }^{2}$ following a study of 1545 cases of head injury in RAF aircrew, had pronounced that only a heavy helmet would give adequate protection and this would interfere with operational efficiency.

I started by analysing reports of head injuries in Naval aircrew resulting from flying accidents, to determine the frequency of various types of injury and, where possible, to relate them to protrusions within the cockpit (e.g. the gyrogunsight). I then studied the mechanics of skull and brain injury, from which were derived the constructional requirements of the helmet. The final product was constructed of layers of woven nylon bonded with phenol formaldehyde resin, with an extra layer coronally across the forehead, the commonest site of injury. Additional 
protection for the forehead was provided by padding of expanded polyvinylchloride, and the helmet harness was made of nylon, which had the property of stretching under tension, thereby tending to absorb an impact as well as distributing it. The helmet was polished to give a low coefficient of friction, so that it would skid over obstructions and minimize the negative $g$ force in an impact. After extensive trials the helmet was accepted by the Navy and 350 were ordered. ${ }^{3}$ The RAF, without reference to the Institute, ordered 3000.

A member of the Institute's staff, a neurologist, had contacts within the motor-racing fraternity. Drivers used a variety of helmets, none of which met the criteria of consonance with the mechanics of skull and brain injury. They were soon replaced by helmets based upon the Mk 1 Aircrew Protective Helmet.

The only motorcyclist's helmet was the Don R (despatch rider's) helmet, consisting of a dome of asbestos fibre with leather cheek-pieces, on which Cairns and Holbourn reported in 1943.4 Although the helmet evidently had a substantial effect in reducing the incidence of skull fractures and concussion it was far from ideal. Maximum protection was provided to the roof of the skull, which is very seldom the site of injury in motorcycle accidents. There was little protection to the frontal area and no protection to the temporal area. However, it had a British Standards number, and in 1956 I wrote to The Lancet suggesting that the BS was unwarranted. The British Standards protested but at the same time invited me to join them in the development of a new BS for an improved motorcycle helmet. I presented the aircrew helmet at a meeting of the Department of Transport's Road-user Sub-committee where a helmet resembling a deerstalker hat, with fore and aft peaks and made of cork, was favoured by the Police Federation and supported by a consultant neurologist from Oxford. The helmet gave no protection against penetration and its high coefficient of friction was enhanced by a covering of grained leather. The aircrew helmet prevailed and, in cooperation with Road Research at Hayes, Middlesex, the Royal Aircraft Establishment and the Snell Memorial Foundation Inc, a new BS was created that was accepted in 32 countries. Today's motorcycle helmets are derived from the new BS version, to which has been added improved coverage with protection to the face.

Today's bicycle helmets come in several very different forms, obviously differing in stability, protective coverage and resistance to penetration. Before considering the question of legislation it is essential to conduct a study of bicycling head injuries in relation to individual helmets, and if necessary, to develop a helmet combining the best features of the existing helmets, following the procedures outlined above for developing protective helmets for other activities. Bicycle-racing enthusiasts might consider stream- lining to be an important requirement; leisure cyclists might attach more importance to appearance. These features would have to be taken into account.

\section{John Rawlins}

Little Cross, Holne, Newton Abbot TQ13 7RS, UK

E-mail: john-rawlins@beeb.net

\section{REFERENCES}

1 Sheikh A, Cook A, Ashcroft A. Making cycle helmets compulsory: ethical arguments for legislation. $J$ R Soc Med 2004;97:262-5

2 Cade S. Injuries of the head and face sustained by RAF aircrews in operational and non-operational flying. Flying Personnel Research Committee (FPRC) 476, July 1942

3 Rawlins JSP. Development of a flying helmet and of a protective helmet. FPRC 847, August 1963

4 Cairns H, Holbourn H. Head injuries in motor-cyclists with special reference to crash helmets. BMJ 1943;i:591-8

\section{Medical care in France}

What a delightful paper from Angus Macdonald (August $\left.2004 J R S M^{1}\right)$. Since retiring to France, I have had two generalists. Both have practised single-handed, with carefully arranged cover to permit a modest amount of time off for postgraduate learning or teaching, and the occasional holiday. Each has worked part-time in hospital; each has conducted his practice on a mixed appointment and open surgery basis. My initial impression was one of a modicum of overprescribing and of overinvestigation, but this was what most patients demanded. I have also had numerous hospital admissions.

The outstanding features of this experience are several. First, the consultation is likely to be laid back, and thorough: as in general practice, half an hour is not uncommon. Second, the patient meets a delightful degree of courtesy. Third, the waiting time for a hospital appointment is seldom as much as two weeks and action is commonly decided on the spot. My non-urgent hip replacement, even when postponed at my request, was done within five weeks of the initial consultation. Of course, the costs of the service in France are high, but the patient puts a higher value upon a service when money changes hands. Litigation is much lower in France, where the great majority of patients appreciate the excellence of the personal service they receive. God forbid that France moves towards the British model of care before I die.

\section{John K Paterson}

18 Allees Arago, 66320 Vinca, France

E-mail: john.paterson@wanadoo.fr

\section{REFERENCE}

1 Macdonald A. French leave. J R Soc Med 2004;17:400-12 


\section{Access to scrotal ultrasonography}

The paper by Mr Allen and his colleagues (June 2004 $J R S M^{1}$ ) is a useful contribution to the debate on the twoweek cancer services and we agree with many of their conclusions. However, we take issue with the comments suggesting that general practitioners should be offered rapid access to scrotal ultrasonography. We have had a large number of inappropriate primary care referrals for scrotal ultrasound, the majority for uncomplicated epididymal cysts, hydroceles and post-vasectomy changes. We have therefore agreed the following criteria as indications for scrotal ultrasound examination:

- Swelling or hardness within the body of the testis

- Hydrocele in a young adult (less than 40 years)

- Testicular pain

- Clinical epididymitis which does not resolve after four weeks of antibiotic treatment

We feel with the increasing burden on the ultrasound service it is more cost-effective for patients, where there is doubt of the diagnosis, to have a urological opinion. There is a need for more training in scrotal examination amongst primary care physicians. We appreciate that an ultrasound showing an innocent condition can be very reassuring for patients but the same reassurance can often be given by a general practitioner who is totally confident in the diagnosis or, if appropriate, by a consultant urologist.

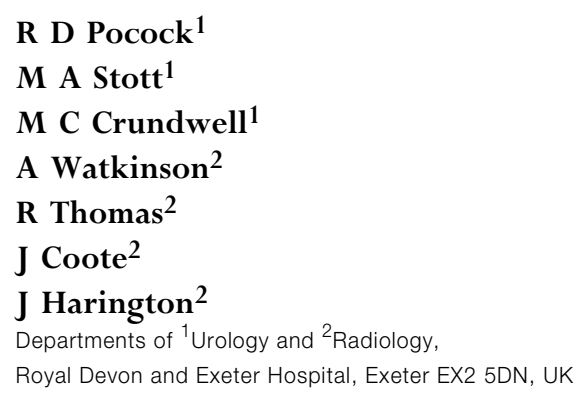

\section{REFERENCE}

1 Allen D, Popert R, O'Brien J. The two-week-wait cancer initiative in urology: useful modernization? J R Soc Med 2004;97:279-281 